\title{
Simulation Modeling Features of Various Machine-Building Enterprise Types
}

\author{
Vitaly Dolgov ${ }^{1,}$, Petr Nikishechkin ${ }^{1}$, Sergey Ivashin $^{1}$, and Nikita Dolgov ${ }^{1}$ \\ ${ }^{1}$ LLC "Digital Systems Factory", Moscow, Russia
}

\begin{abstract}
The paper considers the simulation modeling features of various types machine-building enterprises. A tool set for building simulation models of various production types is proposed. A method of a combined approach for simulation model implementation of mixed production types is proposed and described.
\end{abstract}

\section{Introduction}

Currently, mathematical analysis methods and production processes modeling of machinebuilding enterprises are becoming increasingly relevant [1-3]. This is due to the high requirements for the design level and production units exploitation of machine-building enterprises [4-10].

Simulation modeling is a method of analyzing a system behavior based on the fact that the system under study is replaced by its mathematical model. This makes it possible to simulate the operation of the system and the interaction of all its elements, without experiments on a real object [11-14]. The research object in simulation modeling is created in the form of a logical and mathematical description, which is used to analyze and estimate its functioning by conducting simulation modeling. It is possible to estimate the behavior of the modeling object in time under different initial conditions based on the results of simulation modeling [15-23].

There are three main methods of simulation modeling: agent-based modeling, system dynamics and discrete-event modelling [24,25]. Agent-based modeling is a method of simulation modeling that is used to study decentralized systems, its functioning dynamic is determined by the individual activity results of their elements. System dynamic allows us to implement modeling of the system by constructing mathematical dependencies, graphical diagrams of causal relationships and the influence of some parameters on other parameters over time, and then the model created on the basis of these diagrams is simulated on a computer. Discrete-event modeling is a modeling method based on fixing the events of the beginning and end of the simulated processes, for example: "waiting", "processing", "movement with cargo", "unloading" and others. Discrete-event modeling is the most developed and has a wide range of applications: from transport logistics and queuing systems to production systems. For simulation modeling of machine-building production processes, the discrete-event approach is the most common and allows determining the behavior of production systems over time [Dassault systems, Siemens, Arena]. The main criterion

*Corresponding author: dolgov@digitalfabrika.ru 
determining the need to use simulation modeling to analyze the behavior of production processes is the complexity, and often the impossibility, of describing the functioning of the production system by mathematical dependencies [26-32].

\section{Approaches to simulation modeling of various types of machine-building enterprises}

This paper shows the production and logistics system (PLS) of a machine-building enterprise as an object of modeling, in which the processes of changing and controlling the material flow are carried out when a given production program of output is executed.

The practice of using simulation modeling in relation to machine-building enterprises indicates significant features of the use of simulation modeling methods for various types of production and logistics systems [33-40].

We consider the types of machine-building enterprises, their main features and the feasibility of using different approaches to simulation modeling for each of them. The main classification features of production and logistics systems of machine-building enterprises for determining approaches to modeling production processes are the following: continuity or discreteness of processes, the number of manufactured nomenclature items.

Production and logistics systems of machine-building enterprises can be divided into continuous and discrete systems, depending on the nature of the processes occurring in the systems. Production and logistics systems with continuously flowing production processes represent a set of technological operations that have rigid logistics connections and are performed continuously. The nomenclature in continuous production is measured in units.

Production and logistics systems with discrete production processes are characterized by the presence of intermediate storage of labor subjects between technological operations.

The nomenclature of discrete production can reach thousands or more nomenclature items. Technological solutions for manufacturing products in discrete production are based on the use of flexible logistics links between workplaces and allow the use of alternative technological processes [41-43].

The production type is determined taking into account the technological operations number performed at one workplace, the number of nomenclature items. There are three main types of production: single, serial and mass.

Production and logistics systems with a single and serial production type are characterized by discrete production processes, production and logistics systems with a mass production type are characterized by continuously flowing processes.

A single production is characterized by a large number of nomenclature, the production of which is carried out in small quantities and is not repeated often [44]. The enlarged description of technological processes is used to determine the composition of technological operations without detailing their content. In the technological documentation, the binding of the technological operation to the workplace is not specified. The normalization of the duration for each operation is set in an enlarged manner. The description of the production and logistics system of a single production is poorly formalized. Thus, we can say that there is no formalized description of the "Product-Process-Resource" model. Taking into account these features, the constructed model will have a high level of abstraction and a low level of reliability of modeling results. Therefore, simulation modeling for analyzing the behavior of the production and logistics system of a single production has a narrow scope of purpose and is rarely used in practice.

The manufacture of products in serial production is carried out periodically in specified batches. The production and logistics system of serial production is characterized by a large range of manufactured products, the presence of periodically performed processes. The 
technological documentation contains an operational description of technological processes, including the rationing of operations and their relationship to workplaces (resources).

Mass production is characterized by a small number of nomenclature items and a large volume of output. The production processes description in the production and logistics system of mass production has a high level of detail. Production and logistics systems of mass production are a traditional object of simulation modelling [45-47].

Thus, we can distinguish two main types of machine-building enterprises for which it is advisable to use two types of simulation modeling: serial and mass. We consider the features of building simulation models for each of the selected types of machine-building enterprises (Table 1).

Table 1. Approaches to simulation modeling for various types of machine-building enterprises.

\begin{tabular}{|c|c|c|c|c|}
\hline \multicolumn{3}{|c|}{ Type of machine-building production } & \multirow[b]{2}{*}{$\begin{array}{c}\text { An approach to simulation } \\
\text { modeling }\end{array}$} & \multirow{2}{*}{$\begin{array}{c}\text { A tool for } \\
\text { implementin } \\
\text { g a } \\
\text { simulation } \\
\text { model }\end{array}$} \\
\hline $\begin{array}{l}\text { By the number of } \\
\text { operations } \\
\text { performed at one } \\
\text { workplace }\end{array}$ & $\begin{array}{c}\text { By the variety } \\
\text { of } \\
\text { nomenclature }\end{array}$ & $\begin{array}{c}\text { By } \\
\text { process } \\
\text { type }\end{array}$ & & \\
\hline Single & $\begin{array}{c}\text { Multi- } \\
\text { nomenclature }\end{array}$ & Discrete & $\begin{array}{l}\text { limited use of simulation } \\
\text { modeling }\end{array}$ & - \\
\hline Serial & $\begin{array}{l}\text { Multi- } \\
\text { nomenclature }\end{array}$ & Discrete & $\begin{array}{l}\text { Promising application field } \\
\text { of simulation modeling. The } \\
\text { routing of the material flow } \\
\text { is set by the production } \\
\text { schedule }\end{array}$ & PlantTwin \\
\hline Mass & $\begin{array}{l}\text { Low- } \\
\text { nomenclature }\end{array}$ & Discrete & $\begin{array}{l}\text { The traditional application } \\
\text { field of simulation } \\
\text { modeling. The routing of the } \\
\text { material flow is set using } \\
\text { logical rules }\end{array}$ & $\begin{array}{c}\text { AnyLogic, } \\
\text { PlantSimulat } \\
\text { ion, } \\
\text { DELMIA } \\
\text { and others. }\end{array}$ \\
\hline
\end{tabular}

The production and logistics system of mass production is unstable and has a large number of material flows. The sequence of launching a given nomenclature is determined by the production schedule. The nomenclature volume is measured by hundreds and thousands of nomenclature items. The research conducted by the authors showed that the use of situational logic of routing the material flow does not allow taking into account the priority of manufacturing a particular nomenclature item. The results of simulation modeling are largely determined by the sequence of launching products into production set for modeling. A significant variability in the sequence of launching products into production is the main deterrent to the use of simulation modeling of serial production systems. Therefore, it is proposed to set the routing of the material flow by the production schedule [48-51].

The construction of such a production schedule can be implemented in the MES/APS system and then transferred to the simulation system to simulate its work, taking into account the impact of specified production processes and events (equipment failures, maintenance and repair work, unstable operation execution time, changeover of workplaces, etc.), the onset and duration of which can be set by random variables $[52,53]$.

The production and logistics system of mass small-nomenclature production is relatively stable and has a small number of material flows. The construction of a simulation model of a production system of this type is implemented by a detailed description of the production system elements, the logistics and time relationships between them, as well as the process logic. The sequence of launching products of a given nomenclature, taking into account small number of the products, can be set manually. The routing of the material flow is determined by the situational logic set for the elements of the technological system. Also, it is needed to 
set the logic of interaction of elements of technological, transport and storage equipment with each other when performing production processes.

\section{Tool selection for building simulation models of various production types}

In accordance with the above, the schemes of information flows in the production process modeling of production and logistics systems of serial and mass production types are highlighted (Figure 1).

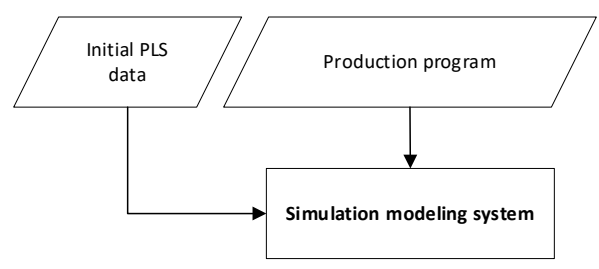

a)

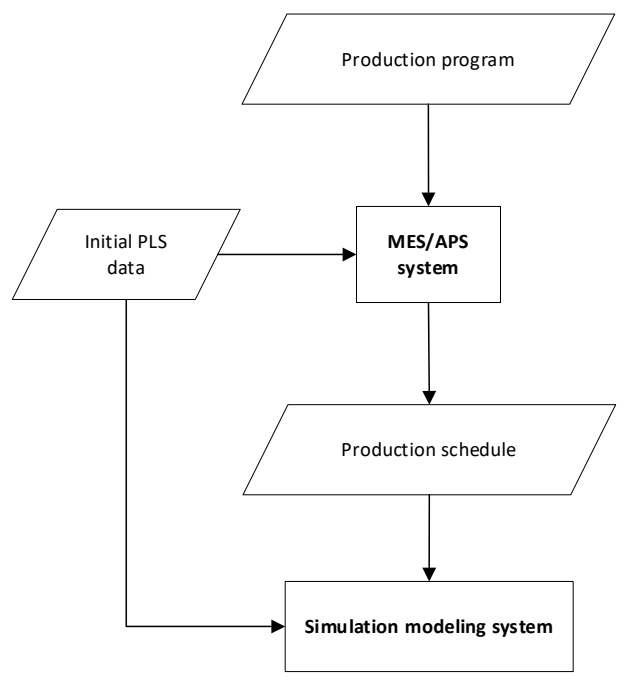

b)

Fig. 1. Information flow diagrams for modeling production processes of production and logistics systems: a) mass production, b) mass production.

Nowadays, there is a wide range of simulation systems that allow us to create simulation models of various processes and conduct experiments on them to achieve your goals. Among the most well-known simulation systems are: PlantSimulation (Siemens, Germany), AnyLogic (The AnyLogic Company, USA), PlantTwin (Amalgam, Russia), Arena (Rockwell Automation USA), DELMIA (Dassault Systèmes SE, France) and others [54-57]. Thus, traditional solutions used in AnyLogic, PlantSimulation, DELMIA, etc.systems, which have developed tools for describing the situational logic of routing material flows, can be used for modeling production and logistics systems of mass production.

It is not recommended to use these systems to form a simulation model of a production and logistics system of a serial type of production. In this paper, to solve this problem, it is proposed to consider the PlantTwin simulation system of the Russian company "Amalgam".

The PlantTwin simulation system allows us to perform simulations according to the production schedule generated by both external systems and the built-in planning module, which is an important advantage of the system. The built-in planning module allows us to check the theoretical feasibility of the production program and generate a production schedule according to one of several planning strategies [58]. Such functionality is important, since in practice it is not always possible to form a production schedule in third-party MES/APS systems when changing input data for modeling "what will happen if?" situations. 


\section{Combined approach application for the simulation models implementation of mixed production types}

Despite the above classification of machine-building enterprises, a real machine-building enterprise often includes separate sections relating to different types of production. Thus, in mass production, sections belonging to the serial type of production can function, for example, tool production. On the other hand, mass production systems can also be used in mass production, for example, a lost-wax casting shop, assembly shops.

In this paper, we proposed a combined approach to the formation of simulation models of production and logistics systems with different production types. The essence of the combined approach is the decomposition of machine-building production into separate production units with different production types and a simulation model construction for each type, taking into account the above features.

The analysis of production and logistics systems with different types of production showed that the following models are the most common:

- production units with a mass production type are suppliers of labor items for units with a serial production type;

- production units with a serial type of production are suppliers of labor items for units with a mass type of production.

In practice, a model of a production and logistics system with a different type of production, in which workshops of one type of production are suppliers and consumers of labor items of workshops with a different type of production is rarely used. For such a model, simulation modeling for is not used.

When building a combined simulation model, it is necessary to ensure consistent production plans for production units with different types of production [59-61].

Thus, to create a combined simulation model of the production and logistics system, an approach is proposed in which the elements of the production and logistics system related to the mass production type are described at the first stage in the AnyLogic modeling environment, where their performance indicators are determined.

Then these elements of the production system are implemented in PlantTwin in the form of "black boxes" with specified time intervals of operation and behavior under various input influences determined during modeling in the AnyLogic environment. Simulation models of the production and logistics system elements of the serial production type are implemented in PlantTwin (Fig. 2).

Figure 2 shows a combined simulation model of a production and logistics system with different production types. The main tool for developing the final simulation model is PlantTwin environment, which describes the operation parameters of various elements of the production and logistics system. Data obtained as a result of their description and modeling in AnyLogic environment are used to describe individual elements of the production system related to in-line production. This approach makes it possible to increase the overall adequacy of the simulation model and describe the operation of a complex production system consisting of various types of processes. 


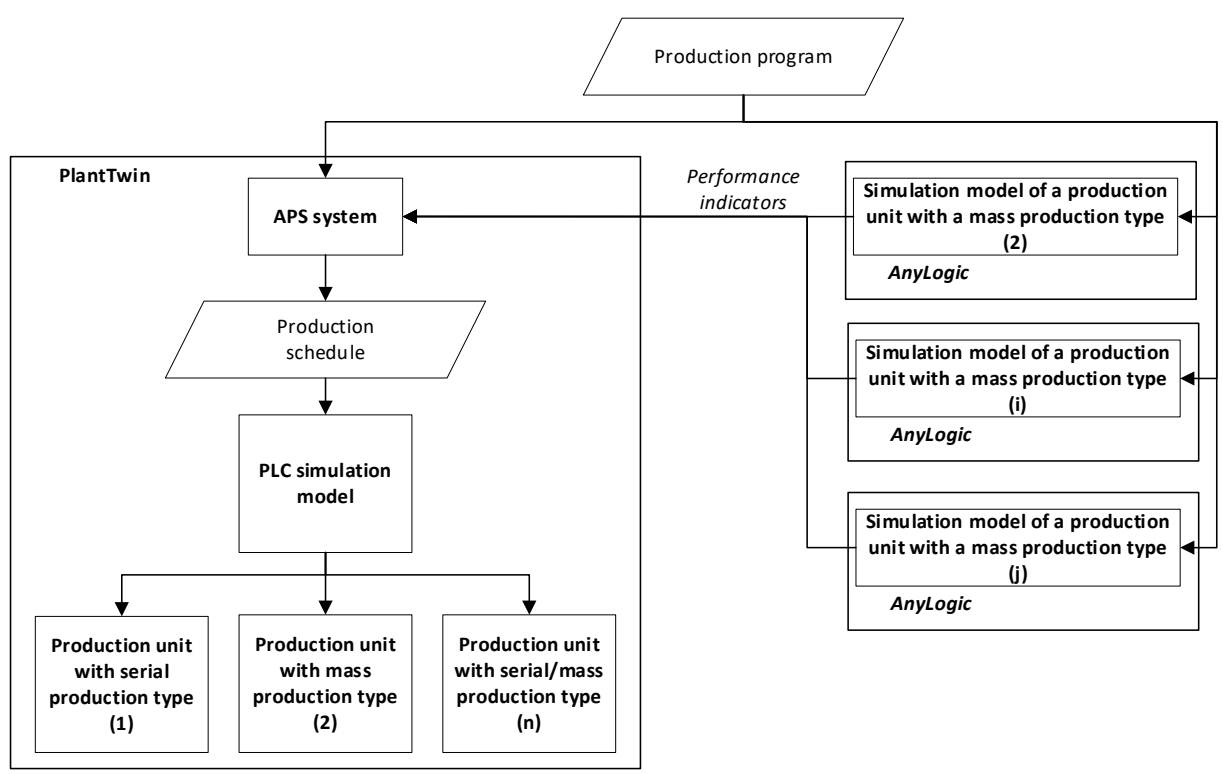

Fig. 2. Simulation model of the production and logistics system of a machine-building enterprise with combined production types.

\section{Conclusions}

In this work we showed that the study of the technological system of single production behavior by simulation modeling is impractical due to the significant nomenclature, the lack of the required initial data. Such a study does not allow to ensure the necessary adequacy of the model.

The paper defines the features of simulation modeling of production processes in mass and serial production types.

Production processes simulation modeling of serial production type production and logistics systems is aimed at analyzing the behavior of the production and logistics system when executing the production program in accordance with a given production schedule.

Simulation modeling of mass production processes is aimed at analyzing the behavior of the production and logistics system when executing a production program in accordance with a given routing logic.

The existing solutions for modeling production processes in various types of production are considered.

The use of the simulation modeling combined method makes it possible to increase the adequacy of modeling production and logistics systems with different types of production, to use the advantages of each of the proposed approaches to the formation of simulation models and to neutralize the disadvantages of using each of them separately.

This work is funded by the state assignment of the Ministry of Science and Higher Education of the Russian Federation, project No. 0707-2020-0025.

\section{References}

1. V. Dolgov, P. Nikishechkin, A. Leonov, S. Ivashin, N. Dolgov, EPJ Web of Conferences 248, 04014 (2021) 
2. O. Balci, R. G. Sargent, Simuletter 15, 15-27 (1984)

3. A. Greasley, Simulation in process design, Manufacturing Engineer 78,173-177 (1999)

4. S. Grigoriev, G. Martinov, Proc. CIRP 14, 517-522 (2014)

5. S. Grigoriev, G. Martinov, Proc. CIRP 41, 858-863 (2016)

6. S. Grigoriev, M. Kozochkin, F. Sabirov, A. Kutin, Proc. CIRP 1, 599-604 (2012)

7. S. Grigoriev, V. Gurin, M. Volosova, N. Cherkasova, Materwiss. Werksttech. 44, 790796 (2013)

8. S. Grigoriev, V. Sinopalnikov, M. Tereshin, V. Gurin, Meas. Tech. 55, 555-558 (2012)

9. S. Grigoriev, G. Martinov, Procedia CIRP 1, 238-243 (2012)

10. S. Grigoriev, V. Teleshevskii, Meas. Tech. 54, 744-749 (2011)

11. A. M. Law, W. D. Kelton, The McGraw-Hill Companies, 760 (2000)

12. S. M. Zahraee, J. M. Rohani, K. Y. Wong, Journal of King Saud University Engineering Sciences, 30, 207-217 (2018)

13. S. Hatami, E. Cowley, C. Morey, In: Simulation Conference. Ieee, 310-313 (1990)

14. S. Wang, D.W. Halpin, Ieee, 1252-1259 (2004)

15. R.R. Barton, In: Simulation Conference, Ieee, 342-353 (2013)

16. D. C. Montgomery, ISBN-10, 1118146921 (2012)

17. J. R. Evans, Pearson Education Inc (2013)

18. O. Balci, ACM Trans. on Modeling and Computer Simulation 11, 352-377 (2001)

19. O. Ciszak, Zeszyty Naukowe Politechniki Poznańskiej 6, 39-45 (2007)

20. Z. Weiss, Wydawnictwo Politechniki Poznańskiej (1998)

21. G. Gordon, Wydawnictwa Naukowo-Techniczne (1974)

22. O. Balci, In Proc. 2003 Winter Simulation Conf. Piscataway, 150-158 (2003)

23. O. Balci, R. G. Sargent, Comm. of the ACM 24, 190-197 (1981)

24. O. Balci, R. G. Sargent, American Journal of Mathematical and Management Science 4, 375-406 (1984)

25. R.E. Nance, R.G. Sargent, Operations Research 50, 161-172 (2002)

26. https://www.anylogic.ru/

27. A. Wank, S. Adolph, O. Anokhin, A. Arndt, R. Anderl, J. Metternich; 6th CIPP Conference on Learning Factories // Procedia CIRP 54, 89-94 (2016)

28. M.-D. Res, V. P. Bresfelean, Procedia Economica and Finance 15, 262-270 (2014)

29. P.Pokorny, A.Kuznetsov, ICMEN 2016 // Procedia Engineering 149, 380-383 (2016)

30. H. S. Hyeok, AL H. M. Al-J. Saad, Yu Haitao, Automation in construction 21, 229-236 (2012)

31. M. Kikolski, Procedia Engineering 182, 321-328 (2017)

32. M. Naig, F. F. Chen, H.-D. Wan, Procedia Manufacturing 11, 593-601 (2017)

33. P.A. Nikishechkin, S. S. Ivashin, V. E. Chernenko, A. A. Malykhanov, N. V. Dolgov, MATEC Web of Conferences 329, 03075 (2020)

34. A. Kutin, V. Dolgov, M. Sedykh, S. Ivashin, Procedia CIRP 11, 476-481 (2018)

35. A. A. Kutin, V. A. Dolgov, M. I. Sedykh, IOP Conference Series: Materials Science and Engineering 23, 012008 (2018)

36. S. Grigoriev, V. Dolgov, P. Umnov, N. Fokin, O. Proshkina, MATEC Web of Conferences 329, 03076 (2020)

37. V. Dolgov, P. Nikishechkin, A. Leonov, S. Ivashin, N. Dolgov, EPJ Web of Conferences 248, 04014 (2021)

38. A. Kutin, V. Dolgov, A. Kabanov, IOP Conference Series-Materials Science and Engineering 448, 012008 (2018) 
39. S. Grigoriev, V. Dolgov, A. Leonov, IOP Conference Series: Materials Science and Engineering 971, 032093 (2020)

40. S. Grigoriev, V. Dolgov, P. Nikishechkin, N. Dolgov, IOP Conference Series: Materials Science and Engineering 971, 032094, (2020)

41. M. Jahangirian, T. Eldabi, A. Naseer, L.K. Stergioulas, T. Young, Eur. J. Oper. Res. 203, 1-13 (2010)

42. J.A.B. Montevechi, A.F. De Pinho, F. Leal, F.A.S. Marins, Proceedings of the 39th Conference on Winter Simulation Ieee Press. 1601-1609 (2007)

43. B. Dengiz, Y.T. Ic, O. Belgin, Math. Comput. Simul 120, 120-128 (2016)

44. N. Selvaraj, Journal of Scientific and Industrial Research 67, 277-281 (2008)

45. S. A. Lyubomudrov, I. N. Khrustaleva, A. A. Tolstoles, A. P. Maslakov, Journal of Mining Institute

240, 669-677 (2019)

46. M. Kikolski, Procedia Eng. 182, 321-328 (2017)

47. A.V. Averchenkov, Vestnik Ufimskogo gosudarstvennogo aviatsionnogo tekhnicheskogo universiteta 3, 76-80 (2012)

48. Y. G. Sandanayake, C. F. Oduoza, International Journal of Advanced Manufacturing Technology 42, 372-380 (2009)

49. R.G. Sargent, Proceedings of The 37th Conference on Winter Simulation, 130-143 (2005)

50. J. P. Womack, Manufacturing Engineering 136, (2006)

51. F.W. Breyfogle III, John Wiley \& Sons Inc, NJ07030 (2003)

52. V. Dolgov, P. Nikishechkin, V. Arkhangelskii, P. Umnov, A. Podkidyshev, EPJ Web of Conferences 248, 04015 (2021)

53. V. Dolgov, V. Arkhangelski, P. Nikishechkin, 2020 International Multi-Conference on Industrial Engineering and Modern Technologies 1-6, (2020)

54. W. D. Kelton, R. P. Sadowsky, D.T. Sturrock, The McGraw- Hill Companies, 658 (2010)

55. W. Małopolski, Czasopismo techniczne 22, 92-93 (2012)

56. D. C. Montgomery, 7th Edition, Wiley, ISBN-10 1118146816, (2012)

57. J. P. C. Kleijnen, In Proc. 1999 Simulation Conf 647-654 (1999)

58. https://plant-twin.com/

59. L. Rabelo, M. Helal, A. Jones, J. Min, Y.J. Son, A. Deshmukh, Winter Simulation Conference Proceedings 2, 1125-1133 (2003)

60. L. Rabelo, M. Helal, A. Jones, H.S. Min, International Journal of Computer Integrated Manufacturing 18, 498-508 (2005)

61. W. Danilczuk, R. Cechowicz, A. Gola, Politechnika Koszalińska 5, 25-42 (2014) 